\title{
Porter's: 'Strategy And The Internet' Revisited
}

\author{
John Hamilton \\ Business School, James Cook University, Cairns, 4870, Australia. \\ John.Hamilton@jcu.edu.au
}

\begin{abstract}
Porter's 2001 'Strategy and the Internet' paper is a key article in the field of on-line strategy. This paper assesses Porter's views in the light of current and past developments. Porter's paper, whilst still thought provoking in many ways, now shows some weaknesses, and in places is no longer as strong as it was in 2001. It presents an approach that attempts to capture past theories and again show their relevance to the on-line world.

This paper suggests that the internet does offer disruptive transitions, does allow new competitiveness models, does allow for new strategic planning approaches, and can deliver personalized one-on-one business to individual customer solutions (termed customerized solutions), and that a service value networks approach offers a mechanism to enable such solutions.

Service value networks focus on the services industry - which engages over $82 \%$ of US employment [14], and over $75 \%$ of Australian jobs [1], and pursue a matrixed networks approach that offers a more complete, and more detailed approach to the delivery of both the business front-end customer engagement cells and to the customer perceived services [7]; [11]. Today, the modern business employs a host of strategic, marketing, servicing, innovation(s), product(s), and economic approaches to delivering services. The service value networks approach offers measurement approaches, indicate engagement pathways, and deliver new management skills to services sector business.
\end{abstract}

Keywords: smart business networks, service value networks, business, customer, encounter, services, servicing, competitive, strategy

\section{INTRODUCTION}

The internet has often been viewed as a means to generate additional or new profit channels. Typically, rather than chasing profits, the perspective - 'grow the business' has been adopted. Customers have been channelled to websites via appeal, ease of access and use, incentives, discounting, advertising, and the like. The focus has been to generate new business models and to unleash products and services in new ways. This has often entailed building a business by generating additional revenue, rather than delivering a service and/or product to the customer at an attractive price (one that also delivers a suitable margin to the business provider).

The pursuit of on-line revenues has often been indirect, rather than direct selling. For example revenue generation has included: (1) click-throughs to other sites; (2) banner advertisements; (3) rotating or fixed image ads; (4) newsletters; (5) advertorials; (6) cross-selling of another firm's services and / or products; (7) auctions; and the like. These revenue streams, do not generally deliver a sustainable competitive advantage, as other competitive operators may readily adopt these channels. Hence, rarely have on-line niches, or unique on-line selling positions been created, and maintained over time. Variations to this situation have arisen. For example, Farmer's Info - and Australian on-line operator has successfully out-competed its four rivals, by incorporating a direct marketing, hard sell system into their business model. This model utilizes the above channels to generate its revenue. EBay has out-competed its auction-house competitors by its services, range of offerings, transaction security, and delivery systems, Amazon has out-competed its rival on-line book sellers, by its range of products, services, and value adds, and Google has out-competed its fellow search engine providers, by continually expanding its offerings, options and services. EBay, Amazon and Google use various combinations of the above channels to compliment their on-line sales.

\section{CURRENT CRITIQUE OF PORTER'S STRATEGY AND THE INTERNET}

\subsection{Economic Value:}

Porter [13] believed variations on the creation of 'economic value' offered stronger pathways to future competitiveness. Here, the value adding by the e-business, and its inherent supporting structures was incorporated with the physical business. Today, an on-line real estate business may offer a virtual tour, with a pay-and-view land and building valuations and/or status and/or government report paid option, or a pay-for-service property documents search. This approach delivers a fee-for-service variation, compared to that traditional meeting with the real estate agent, and then paying for selective pieces of information. This principle remains a solid option to incorporate into an on-line strategy. Porter suggests further improvements draw on the incorporation of both the industry and its supporting supplier structures. For example, today an on-line real estate business may draw on its partnering 
networks to build and present, upon customer request, a pay-for-service relevant on-line property and location price-comparison tables, travel facilities, and GPS topology maps. Again a 'bricks-and-clicks' strategic approach to the business model is of value.

Recently, the e-business model has further improved incorporating focused logistics and strategic management into the solution. Companies like FedEx now offer 4PL solutions for any businesses - on-line (clicks), off-line (bricks) or both on-line and off-line (bricks-and-clicks). 4PL solutions effectively eliminate business concerns regarding supply, storage, pick-up, and delivery of the customer requested business value added items. Such logistics providers may also be incorporated into the business, or e-business strategic solution [5]. But, competitive advantage - whilst more complicated; is not assured. Other businesses soon copy this model, and competitive price pressures as Porter suggested, continued to drive such models towards lowest cost, and low profit margin, solutions. For example a new strong entry into the on-line dating market will further spread the customer base and so put downward pressures on pricing. Similarly, on-line travel agencies have put downward pressures on airline prices, and created narrower margins for on-line travel agencies.

\subsection{Value Adding Services}

Another business solution to remain distinctive was to add more services and/or products to their c-business portfolios. This strategy presents an ever expanding, and increasingly complex e-business model, but again, direct copycat competitors, or substitute competitors soon emerge. For example, in the real cstate industry realestate.com has several competitors, and has remained competitive by adding services and expanding its links to local agents. Microsoft has continually grown its business services to capture and remain relevant to new markets. Sony has developed a MySony and loyalty section, allowing its key purchasers to have previews of upcoming products and services. All these solutions are costly, and deliver increasingly complex on-line models.

\subsection{Technologies}

Porter suggested building on existing businesses and incorporating latest technological solutions offered pathways towards competitiveness. This strategy today is exemplified by the 'bricks-and-clicks' model combining the physical business and virtual e-business models into a complementary network. This model remains the most successful on-line and off-line business solution, and it works across many industries. For example, the US retailer Sears, the Commonwealth Bank of Australia, and the logistics providers UPS and FedEx and the car manufacturer $G M$ all use this dual environment model, but each uses it differently.

In 2004, Hamilton and Selen applied Porter's model to the on-line real estate industry, and further built on Porter's overall premise [12]. They suggested strategic positioning and customerization offered strong pathways towards higher levels of on-line competitiveness. This, in effect, mirrored Porter's views of building on proven principles of effective strategy to deliver competitive advantage, but in a virtual world.

\subsection{Disruptive Transitions}

Porter's next view was that the internet was not disruptive to most industries and established companies, and that the internet merely improved competitive advantage in an industry. Hence, as all businesses adopted the internet, competitive advantage via this medium, would dissipate. Today, this point may often be found to be inadequate. The move to from low Ievels of technological integration to higher levels often requires the adoption of new technologies and systems, and these processes are often disruptive - requiring retooling, reprogramming, new intelligence and new processes. Thus new competitiveness levels are often achievable.

A services industry may operate as a low level service integration model where information and business solutions show low levels of integration. For example, the business stock control may not be integrated with the logistics and/or the suppliers. In the case of pharmacies in Australia, the national prescriptions register has all pharmacies linked to a federal government database, but in several individual pharmacies automatic inventory management (and supply chain integration), marketing, human resources and financial databases options - when in use, are rarely incorporated into the industry's value network solutions. This low level integration typifies a busy individual store, with little or no computerized operations, and it constitutes the oldest and least value adding model. It represents a low service integration model.

The next level of customer interactivity captures those businesses with degrees of supply chain inter-connectivity and some networked (computerized) operations. Here the business stock controls, linked to the logistics providers and suppliers, act in harmony to deliver greater levels of customer servicing and customer perceived performance. To move from the low service integration model up to this service supply chain integration model normally requires the incorporation of new technologies and systems. This change is not incremental. It requires new approaches and greater sophistication, and it represents a disruptive transition.

Businesses delivering higher level, responsive, demand-driven solutions may search and locate responses to in-depth customer requests by tapping their well-integrated network information systems. Generated responses are then relayed to the customer - hopefully delivering enhanced customer perceived value. In addition, the customer-related business database is 
updated with each new customer request (and / or variation). Such additions may thus increase the response capabilitics of the business. This model is the demand chain model.

The next level of complexity is the customer relationship management (CRM) transition. CRM delivers the methodologies, software and internet capabilities necessary to enable the business to manage its customer relationship in an organised way. It targets improving the business to customer interaction, but it does not deliver the tools to customerize or build one-on-one relationships, as it employs gap analysis type procedures to align its business and customer sectors. This approach was not found to be utilized by pharmacy survey respondents to this study, but a couple of combined on-line and off-line pharmacies are operating close to this model.

The current peak level business integration model captures the industry-wide, environmentally-interactive service value networks (SVNs). Here, fully-integrated networked computerized solutions may be intelligently delivered to the customer, via the serving staff, or the business representative, or via direct on-line customer engagement into the business network. In response to a customer generated request, the SVNs engage the business intelligence tools, and both assess and deliver: agile, dynamic, flexible, customerized business-customer cncountcrs - oncs capable of offering 'elevated-services', and / or 'added-value' solutions. These highly complex 'living' networks are constructed as a reengineered disruptive business model - one very different to the next most advanced business model - the service demand chain integration model.

Thus, although different levels, and degrees of interaction, are displayed by the various models, all display a commonality in that to enable an exchange to occur, the business and customer interaction systems actually funnel into a final business-customer encounter. This sharing and / or new-knowledge transfer, may be used to enhance understanding of the relevant key business-customer encounter pathways (or channels), and to show the potential relevance of a SVN approach for the industry. This procedure allows parameters relevant to the front-end business-customer encounter interface to be captured, sifted, and sorted. Ultimately premium quality business solutions are delivered. Hence Porter's view of the internet as a non-disruptive influence is no longer correct, and business's may use these disruptive transitions as new strategic pathways to competitiveness.

\subsection{Traditional Versus Latest Strategies}

Porter suggested that whilst technology, and internet technologies, may strengthen advantages, service and/or product uniqueness, proprietary content, distinctive physical activities and other traditional strengths would continue to deliver competitive advantage. This view does not allow for value add sources, like marketing, and innovation which delivers competitive advantage via numerous direct and indirect pathways. For example, SVNs Hamilton [7]:[8]:[9]:[10]:[11], shown in Figure 1, capture and intelligently link the (1) business back-end processes; business applications; business infrastructure and associated electronic / mobile backbones throughout the entire organisation, and across its relevant levels (including executive, management, operational); (2) environmental interactions impinging on these networks (and the relevant constituent business and customer systems). Between the business and the customer is the business-customer encounter - here the SVNs capture the (3) business-customer interactors (that act under the prevailing environment) across this business to customer divide. Finally, the (4) front-end of SVNs captures the customer (as individuals, as individual customerized units, or as customer-segments), along with the relevant front-end external influences that may affect the customer and/or the business-customer encounter.

SVNs also capture both physical and virtual SVNs components, as both may participate in the business-customer encounter. These business-customer encounter pathways (or touch-points) may improve (or impede) the delivery of the customer desired SVN outcomes, and further elucidate the key strategic business performance and value dimensions that influence the effective management of the SVN encounter with the customer.

Thus SVNs may be defined as the networked and aggregated (both vertically and horizontally) systems that capture, and focus, the business, the customer, and the environmental cell blocks and their interactors into a front-end matrix that is capable of delivering targeted, bi-directional, customer-centric solutions. Such a field of research delivers new uniqueness propositions, and distinctive physical and virtual activities, and so makes the internet an integral part of the business strategy. As numerous communication channels today are virtual, the internet, and its associated mobile devices, are delivering new pathways to competitiveness, and are requiring new strategies.

Porter believed the internet to be a complimentary tool, rather than a change to the existing ways of doing business. This point requires clarification, and today is not an adequate representation of the current e-business model. The SVNs approach shows the internet and its associated internal matrixed business networks linked to environmental factors and specifically targeted customers, is capable of delivering new zones of competitiveness.

Strategically, Porter projected most successful 'dot-coms' would focus on creating benefits that were customer focused and required customer pay-for-service, and this would require the broadening of value chains into other 
virtual and physical activities. Today, Porter's views are only partially correct. Many 'dot-coms', like E-Bay, Yahoo, Google, Amazon, and Farmers Info, have successfully developed new e-business models, that only in-part require fee-for-service, and also capture revenue streams from business partnering networks, external business advertisers, other business and government contributors, and commissions. Other e-business operators like statistical data collectors, pay customers for their contributions. These e-business added value solutions often tap their value chains and cross-reference these across their value networks, thereby delivering added value solutions for their customers. Some also draw information or specific service/product variations from their external peripheral and casual business acquaintances into these value networks. Hence, many successful on-line businesses build their added value customer solutions from their available value networks, and today many viable operations do not focus on pay-for-service. Indeed new CRM strategies and e-marketing strategies are unlocking new pathways towards a more sustainable competitiveness position for the business.

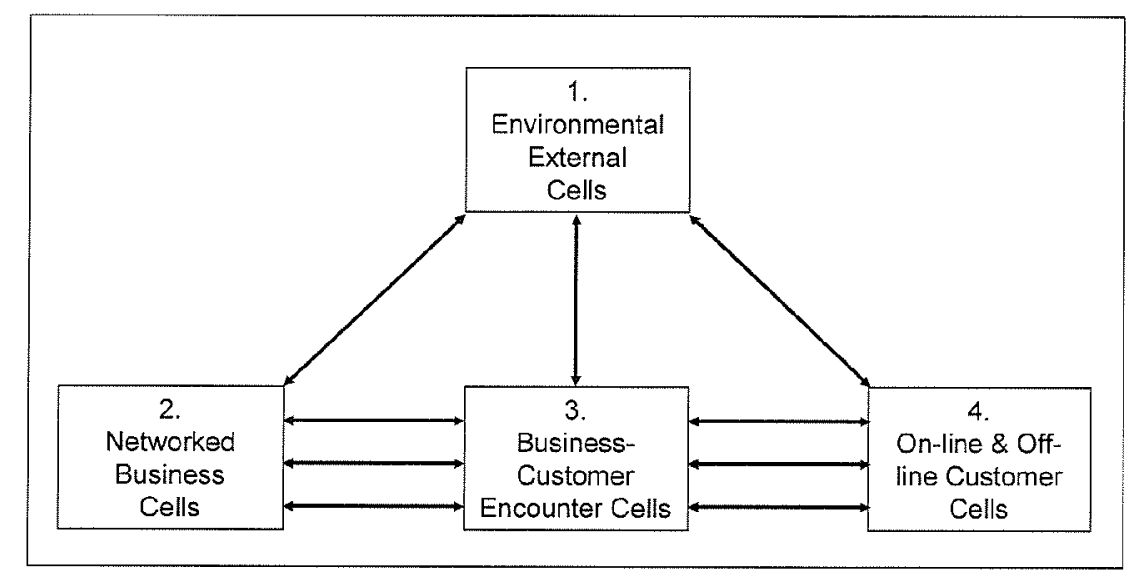

Figure 1: Four Networked SVNs Business, Customer and Environmental Cell Blocks, O Hamilion [11]

In 2001, Porter [13] concluded businesses should develop the internet as part of their overall strategy, focusing on making their traditional activities better, and/or implementing new combinations of virtual and physical activities that were not previously possible. Today, smart businesses practicing SVNs approaches, matrix their entire business communications network including the: (1) internet and mobiles, (2) the value networks, (3) externally incorporated peripheral and casual business contributors, (4) effectors from the immediate and global environments and (5) customer interaction channels into their overall strategy. Here, if suitably directed, each contributes to, affects, and is affected by, the overall business competitiveness position.

\section{THE FUTURE - USING A PHARMACY INDUSTRY EXAMPLE}

The pharmacy industry, shown in Figure 2, operates as a SVN, but only certain pathways engage the customer. Thus in developing strategy and a competitive position this industry and its constituent operations may direct its energy into refining its innovative practices, its overall communications and web strategies, its marketing strategies, and its servicing and product delivery. These channels are networked, hence variations to the network caused by business changes, customer request variations, or environmental changes, have secondary, tertiary and ripple effect. Hence, changes must be monitored across the network, and adjustments to ensure front-end deliverables match the customer requirements. This model is then capable of self adjusting its positioning. To prevent drift, and maintain business- customer encounter alignment, resurveying is conducted, and data adjustments are incorporated.

Today, there are new ways to generate business competitiveness - networking industries, or business chains, or supply-demand chains; market research capturing CRM, SEM analysis, building targeted solutions, and using business intelligence tools to mine for customer specific solutions. These models do not just complement the physical model. They deliver the matrixed nerve system whereby new knowledge may be elucidated. They interconnect with the external world, and seek out customer and/or business comparisons, ideas, value adds. These complements are drawn into the matrixed knowledge base and are specifically targeted to the individual customer and their requirements. 


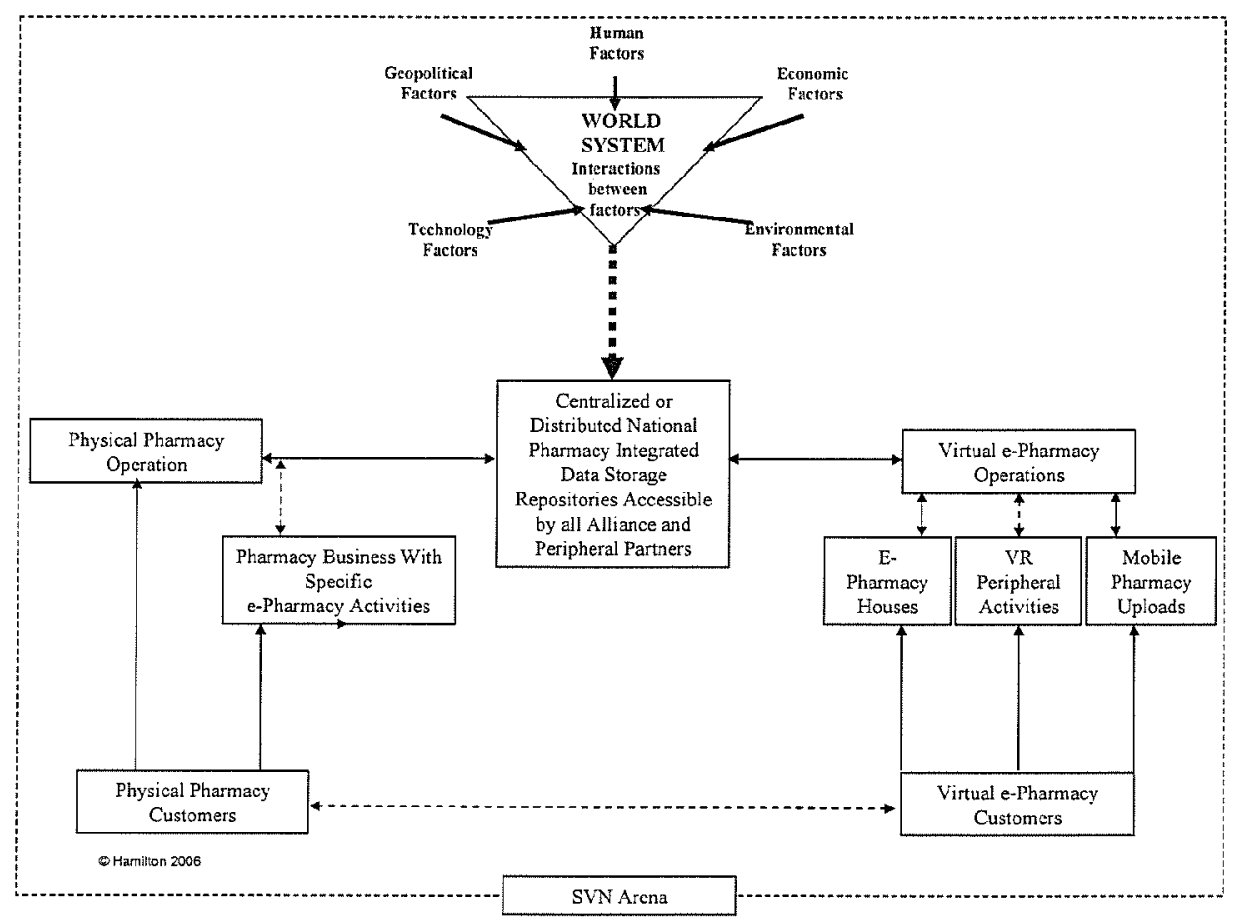

Figure 2: SVN - Global Perspective, adapted from Anwar and Hamilton .

\section{CONCLUSION}

For 2001 Porter's HBR paper was a defining 'strategy and the internet' paper, and it was suitably representative of the internet and its structure. At the time, some researchers argued that internet rendered many strategies obsolete. In contrast, Porter argued the internet tended to weaken industrial profitability without providing proprietary operational advantages, and that companies should use the internet strategically to complement the traditional physical ways of competing. Even today many aspects of this paper remain valid. However, some inaccuracies have since emerged. Today, the business should be viewed as one that encapsulates a networked solution combining both the physical and the virtual models into one smart business network. This smart business network should encapsulate the available business SVNs, which should be optimized and then intelligently developed across the business matrix.

These SVNs offer new ways to generate competitiveness. They deliver matrixed nerve systems whereby new knowledge may be sourced, studied, developed and elucidated. They interconnect with the external world, and seek out customer and/or business comparisons, ideas, and value adds. These complements are drawn into the matrixed knowledge-base, and may be tuned to specifically target the individual customer and their requirements, in a one-on-one business-customer encounter process termed customerization. Thus Porter's
2001 Strategy and the Internet model, which offered a great starting point has now moved on, capturing new business dimensions and intelligences. No longer is the lowest cost, or niche provider the only likely surviving e-model, and traditional strategy must be adapted to the internet in new ways that may focus on customerized outcomes drawn form the across the entite business matrix of SVNs. Thus, the manager of the future will mange using new tools, and higher levels of business cell networked intelligence will cnable covariances of cells and interaction pathways to be measured, monitored and refined. Hence SVNs alignment of the busincss to its customers and with the environment will become a key factor in delivering long-term competitiveness. Thus a new level of 'Strategy and the Internet' is emerging.

\section{REFERENCES}

[1] ABS. Economic contribution of the service industries sector, Australian Year Book 2006, Ch 20, Canberra, Aust: ABS, 2006.

[2] Anwar S., \& Hamilton, J. "Tourism into the Future Towards 2020, and Beyond", Tourism Recreation Research Journal, Vol. 30, No. 3, pp. 77-85, 2005.

[3] Christensen, C., \& Anthony, S. "Cheaper, faster, easier: Disruption in the service sector", Strategy and Innovation, Vol. 2, No. 1, pp. 56-65, 2004.

[4] Evans, N. Business Agility: Strategies for Gaining Competitive Advantage Through Mobile Business 
Solutions, Upper Saddle River, NJ: Prentice-Hall, 2002.

[5] Gunesh, R., \& Hamilton, J. "Incorporating Customer Interface Marketing Design Elements to Leverage Strategic Positioning in the On-line Real Estate Industry", 3rd International Conference on Business, Vol. 3, No. 1, pp. 1-9, Honolulu, May 23-27, 2003.

[6] Hamilton, J. "E-Logistics Comparative Positioning Model: A Multi-National Enterprise Airline Study", 4th International Conference on Electronic Business, International Academic Publishers, International Academic Publishers, Vol. 4, No. 1/2, pp. 93-100, Beijing, Dec 5-9, 2004.

[7] Hamilton, J. "Service Value Networks: Value, Performance and Strategy for the Services Industry", Journal of Systems Science and Systems Engineering, Vol. 13, No. 4, pp. 469-489, 2004.

[8] Hamilton, J. "The Virtual Service Value Network: Disruptive Technology Delivering Competitive Advantage for the Services Industry, 4th International Conference on Electronic Business, International Academic Publishers, Vol. 4, No. 1/2, pp. 211-218, Beijing, Dec 5-9, 2004.
[9] Hamilton, J. "Service Value Networks: a New Approach to Performance and the Delivery of Services", The E-Business Review, Vol. 5, No. 1, pp. $66-71,2005$.

[10]Hamilton, J. "Business-customer alignment in the Australian pharmaceutical industry", International Journal of E-Business, Vol. 4, No. 5, pp. 401-420, 2006.

[11]Hamilton, J. "Delivering Service Valuc Networks: Smart Business", 36th Western Decision Sciences Institute Meeting, pp. 227-232, Denver, April 4-7, 2007.

[12]Hamilton, J., \& Selen, W. "Enabling Real Estate service chain management through personalised Web interfacing using QFD", International Journal of Operations and Production Management, Vol. 24, No. 3, pp. 270-288, 2004.

[13]Porter, M. "Strategy and the Internet", Harvard Business Review, Vol. 79, No. 3, pp. 63-78, 2001.

[14]WTO Anon. (2003). "World Trade Organization Services Liberalization Talks", WTO March Report, Geneva, Switzerland: WTO. 